\title{
European Marine Biodiversity Monitoring Networks: Strengths, Weaknesses, Opportunities and Threats
}

\section{OPEN ACCESS}

Edited by:

Marianna Mea

Jacobs University of Bremen, Austria

Reviewed by:

Patrick Georges Gillet,

Université Catholique de l'Ouest,

France

José Lino Vieira De Oliveira Costa

University of Lisbon, Portugal

*Correspondence:

Joana Patrício

joanamateuspatricio@gmail.com

Specialty section:

This article was submitted to

Marine Ecosystem Ecology,

a section of the journal

Frontiers in Marine Science

Received: 16 June 2016

Accepted: 24 August 2016

Published: 08 September 2016

Citation:

Patrício J, Little S, Mazik K, Papadopoulou K-N, Smith CJ, Teixeira $H$, Hoffmann $H$, Uyarra MC, Solaun O, Zenetos A, Kaboglu G, Kryvenko O, Churilova T, Moncheva S,

Bučas M, Borja A, Hoepffner N and Elliott M (2016) European Marine Biodiversity Monitoring Networks:

Strengths, Weaknesses, Opportunities and Threats. Front. Mar. Sci. 3:161

doi: 10.3389/fmars.2016.00161

\begin{abstract}
Joana Patrício ${ }^{1 *}$, Sally Little ${ }^{2,3}, K_{\text {Krysia Mazik }}^{3}$, Konstantia-Nadia Papadopoulou ${ }^{4}$, Christopher J. Smith ${ }^{4}$, Heliana Teixeira ${ }^{1}$, Helene Hoffmann ${ }^{1}$, Maria C. Uyarra ${ }^{5}$, Oihana Solaun ${ }^{5}$, Argyro Zenetos ${ }^{6}$, Gokhan Kaboglu ${ }^{7}$, Olga Kryvenko ${ }^{8,9}$, Tanya Churilova ${ }^{8,9}$, Snejana Moncheva ${ }^{10}$, Martynas Bučas ${ }^{11}$, Angel Borja ${ }^{5}$, Nicolas Hoepffner ${ }^{1}$ and Michael Elliott ${ }^{3}$

${ }^{1}$ European Commission, Joint Research Centre (JRC), Directorate for Sustainable Resources, Ispra, Italy, ${ }^{2}$ School of Animal, Rural and Environmental Sciences, Nottingham Trent University, Southwell, UK, ${ }^{3}$ Institute of Estuarine and Coastal Studies, University of Hull, Hull, UK, ${ }^{4}$ Hellenic Center for Marine Research, Institute of Marine Biological Resources and Inland Waters, Heraklion, Greece, ${ }^{5}$ Marine Research Division, AZTI, Pasaia, Spain, ${ }^{6}$ Hellenic Center for Marine Research, Institute of Marine Biological Resources and Inland Waters, Athens, Greece, ${ }^{7}$ Institute of Marine Sciences and Technology, Dokuz Eylül University, Izmir, Turkey, ${ }^{8}$ A. O. Kovalevsky Institute of Marine Biological Research of RAS, Sevastopol, ${ }^{9}$ Marine Hydrophysical Institute of RAS, Sevastopol, ${ }^{10}$ Institute of Oceanology-Bulgarian Academy of Science, Varna, Bulgaria,

${ }^{11}$ Marine Science and Technology Center, Klaipéda University, Klaipéda, Lithuania
\end{abstract}

By 2020, European Union Member States should achieve Good Environmental Status (GES) for 11 environmental quality descriptors for their marine waters to fulfill the Marine Strategy Framework Directive (MSFD). By the end of 2015, in coordination with the Regional Seas Conventions, each EU Member State was required to develop a marine strategy for their waters, together with other countries within the same marine region or sub-region. Coherent monitoring programs, submitted in 2014, form a key component of this strategy, which then aimed to lead to a Program of Measures (submitted in 2015). The European DEVOTES FP7 project has produced and interrogated a catalog of EU marine monitoring related to MSFD descriptors 1 (biological diversity), 2 [non-indigenous species (NIS)], 4 (food webs), and 6 (seafloor integrity). Here we detail the monitoring activity at the regional and sub-regional level for these descriptors, as well as for 11 biodiversity components, 22 habitats and the 37 anthropogenic pressures addressed. The metadata collated for existing European monitoring networks were subject to a SWOT (strengths, weaknesses, opportunities, and threats) analysis. This interrogation has indicated case studies to address the following questions: (a) what are the types of monitoring currently in place? (b) who does what and how? (c) is the monitoring fit-for-purpose for addressing the MSFD requirements? and (d) what are the impediments to better monitoring (e.g., costs, shared responsibilities between countries, overlaps, co-ordination, etc.)? We recommend the future means to overcome the identified impediments and develop more robust monitoring strategies. As such the results are especially relevant to implementing comprehensive and coordinated monitoring networks throughout Europe, for marine policy makers, government agencies and regulatory bodies. It is emphasized that while many of the recommendations given 
here require better, more extensive and perhaps more costly monitoring, this is required to avoid any legal challenges to the assessments or to bodies and industries accused of causing a deterioration in marine quality. More importantly the monitoring is required to demonstrate the efficacy of management measures employed. Furthermore, given the similarity in marine management approaches in other developed systems, we consider that the recommendations are also of relevance to other regimes worldwide.

Keywords: Marine Strategy Framework Directive (MSFD), biodiversity, Good Environmental Status (GES), regional sea, pressures, SWOT analysis

\section{INTRODUCTION}

By 2020, European Union Member States should achieve GES (Good Environmental Status) for their marine waters to comply with the Marine Strategy Framework Directive (MSFD; $2008 / 56 / E C)$. By the end of 2015, in coordination with the Regional Seas Conventions (RSC), each EU Member State was required to develop a marine strategy for their waters, together with other countries within the same marine region or subregion. Under the MSFD, reporting on GES should be carried out at a Regional Sea level (although marine sub-regions and subdivisions may be used to take into account the specificities of a particular area), which thus requires broad-scale monitoring with the potential to account for ecosystem level changes in response to both anthropogenic and natural pressures. In order to achieve this, assessment of GES under the MSFD is divided into 11 qualitative descriptors that collectively aim to cover the threats, pressures, and status of the whole marine ecosystem to give a complete picture of environmental status (Borja et al., 2013). Some of those descriptors relate to background conditions, some to pressures and some to impacts on the natural or social systems. Specific requirements of the MSFD include: (i) coordination of monitoring between EU Member States, (ii) that monitoring must be compatible with the EU Water Framework Directive (WFD), and Birds and Habitats Directives, and (iii) that monitoring must incorporate physical, chemical and biological components. It is necessary to consider the fundamental niches (i.e., sea bed, water column, and ice) to which each of these 11 descriptors relate, as well as the biological components (e.g., microbes, fish, see below). The assessment of each aspect of the marine environment requires an indicator (or usually a suite of indicators) to inform on state, and these indicators require data collected through monitoring (Shephard et al., 2015) although existing indicators may potentially leave gaps in current monitoring as new needs arise through the MSFD (Teixeira et al., 2014; Berg et al., 2015). Borja and Elliott (2013) describe monitoring sensu stricto as "the rigorous sampling of a biological, physical and/or chemical component for a well defined purpose, against a well defined end-point" and state that this may be in relation to the detection of trends away from an accepted starting point, non-compliance with a legal threshold, and/or comparison to standards, baseline or trigger points. However, current environmental management refers to different types of monitoring, all of which serve different purposes, with differing methods and analysis of the results. For example, Elliott (2011) identified 10 types of monitoring, two of which are of specific relevance to the MSFD: (1) Surveillance monitoring which enables the detection of spatial and temporal trends and, where necessary, leads to management action (for example, the detection of climate change trends), and (2) Condition monitoring to determine the present status of an area, and to detect change in condition over time (for example the health of the environment). However, once any deleterious change has been detected then investigative or diagnostic monitoring will be required to determine the cause-effect relationship, again linking to management actions.

The results of these types of monitoring, which each cover a spatial extent and/or a temporal duration and frequency, then requires feedback into management and policy decisions (Gray and Elliott, 2009). It is axiomatic that a system cannot be managed unless it is monitored thus giving data to show the status of the system and the results of the management measures implemented, hence taking all these elements together then requires and produces a monitoring program. Zampoukas et al. (2014) defined a Monitoring Program as "all substantive arrangements for carrying out monitoring, including general guidance with cross-cutting concepts, monitoring strategies, monitoring guidelines, data reporting and data handling arrangements. Monitoring programs include a number of scheduled and coordinated activities to provide the data needed for the ongoing assessment of environmental status and related environmental targets." A monitoring program can include one or several monitoring activities, defined as "the repeated sampling and analysis in time or space of one or more ecosystem components and carried out by an individual agency or institution. Data and marine information are obtained on a routine or specific basis, using sea surveys, remote sensing (i.e., teledetection), ferry boxes, data mining, or any other way." By expanding the comments of Zampoukas et al. (2014), monitoring programs should have an adequate coverage, in terms of accounting for current pressures and impacts on both natural and social systems but should also be adaptable to address environmental variability associated with emerging issues (see also Scharin et al., 2016). For the purposes of the MSFD, monitoring also needs to be coherent and coordinated, whereby EU Member States within the same region or sub-region follow agreed methods and focus on agreed biotic and abiotic components. This ensures that reporting is comparable across sea areas and can be incorporated into assessing GES at a Regional Sea level (Cavallo et al., 2016).

The nature and scale of marine environmental monitoring within Europe, was assessed within the DEVOTES FP7 project 
(DEVelopment Of innovative Tools for understanding marine biodiversity and assessing GES, www.devotes-project.eu). This assessment involved compiling a catalog of marine biodiversity monitoring programs at the regional sea level (focusing on MSFD Descriptors where biodiversity is relevant: D1, biological diversity, D2, non-indigenous species (NIS), D4, food webs, and D6, sea-floor integrity). The catalog highlights:

- the MSFD descriptors and biodiversity components being either directly targeted or indirectly addressed through monitoring under other legislative obligations;

- the specific habitat type targeted;

- particular pressures for which the monitoring was designed;

- the marine regions and sub-regions where particular monitoring activities are taking place;

- the time series and frequency of the data collection, to assess temporal change, and

- collaboration between different countries within and between the RSC.

To meet the requirements of the MSFD in terms of demonstrating GES, a detailed understanding of the above requires answering the following questions: (a) what are the types of monitoring currently in place? (b) who does what and how? (c) is the monitoring fit-for-purpose for addressing the MSFD requirements? and (d) what are the impediments to better monitoring (e.g., costs, shared responsibilities between countries, overlaps, co-ordination, etc.)?

By identifying current monitoring, this exercise aimed to highlight omissions in descriptors, biological components and habitats in particular marine regions or sub-regions and provide a broad overview of the spatial distribution and temporal intensity of monitoring activities. In particular, it aimed to identify programs or combinations of programs that will address the requirements of the MSFD, thus enabling decisions to be made about the cost-effectiveness of future monitoring. This high level assessment of the adequacy of current monitoring, in terms of spatial and temporal scale, in turn will allow the identification of components requiring inclusion in existing monitoring programs or the requirement for the development of entirely new monitoring programs. All of these aspects together constitute what is regarded here as a fit-for-purpose monitoring program.

\section{MATERIALS AND METHODS}

\section{Devotes Catalogue of Marine Biodiversity Monitoring Networks}

Information was compiled regarding the current status of marine biodiversity monitoring, and in particular of the MSFD descriptors $1,2,4$, and 6 . In order to have an adequate spatial coverage of monitoring networks throughout the European Regional Seas, we first identified monitoring activities within the EU Member States or Regional Seas covered by the DEVOTES partners and then circulated the catalog outside that partnership for completion. Several other countries (EU Member States and third countries) voluntarily and enthusiastically provided information to this catalog. However, those areas with which DEVOTES has a stronger link have a more comprehensive coverage in the catalog (Figure 1). The catalog and Patrício et al. (2014) form the basis and common authorship of this manuscript. It is however recognized that monitoring programs in EU Member States are subject to regular amendment/change and as such the catalog requires regular updating to reflect the current status of monitoring activities throughout Europe. The catalog is publicly available at http://www.devotes-project.eu/devotes-release-new-versioncatalogue-monitoring-networks/. Despite the slightly incomplete nature, we consider that the catalog provides sufficient coverage to give the main lessons to be learned from this first, broad overview of European monitoring activities. It enables detailed analysis to support the harmonization of monitoring throughout Europe.

The focus of the catalog was on monitoring solely related to biodiversity (i.e., relating to MSFD D1, D2, D4, and D6) and not on determinants for human food provision or quality or physicochemical aspects (unless the latter are collected as supporting data for biotope characterization and biological parameters).

The catalog is presented in the above site as an EXCEL file containing two main tables:- "MONITORnetworks catalogue" and the parameters table "Param \& physico-chemical data." The database is structured into three levels:

(1) Monitoring program level: this describes the general features of each monitoring activity, including the program name, the website and the time-series of the monitoring to enable users to find the full details (where available) of monitoring activities, methods, indicators, and parameters associated with a specific program. The geographical scope of each program is indicated through participation at national, EU, Regional Sea or local scale (e.g., for research or a single organization operating in a small area) together with information on the Regional or sub-regional seas to which the program applies.

The MSFD descriptor, the biodiversity component and the specific habitat type targeted by each program were identified to allow an assessment of the extent to which current monitoring practices address the ecological components. The biodiversity components include Microbes, Phytoplankton, Zooplankton, Angiosperms, Macroalgae, Benthic Invertebrates, Fish, Cephalopods, Marine Mammals, Reptiles, and Birds. The choice of biodiversity components was based on official MSFD documents and a related Commission Staff Working Paper (EC, 2012). The habitats (fundamental niches) include Seabed, Water column and Ice habitat. The categories adopted for habitat types followed the EU Commission Decision (EC, 2010) and EU Commission Staff Working Papers (EC, 2011, 2012) where it was agreed that the "use of these types provides a direct link between habitats assessed under Descriptor 1 and the substratum types to be assessed for Descriptor 6) and the European EUNIS habitat classification scheme" (EC, 2011, p. 18). In each case, the associated physico-chemical data collected (in the Param \& 


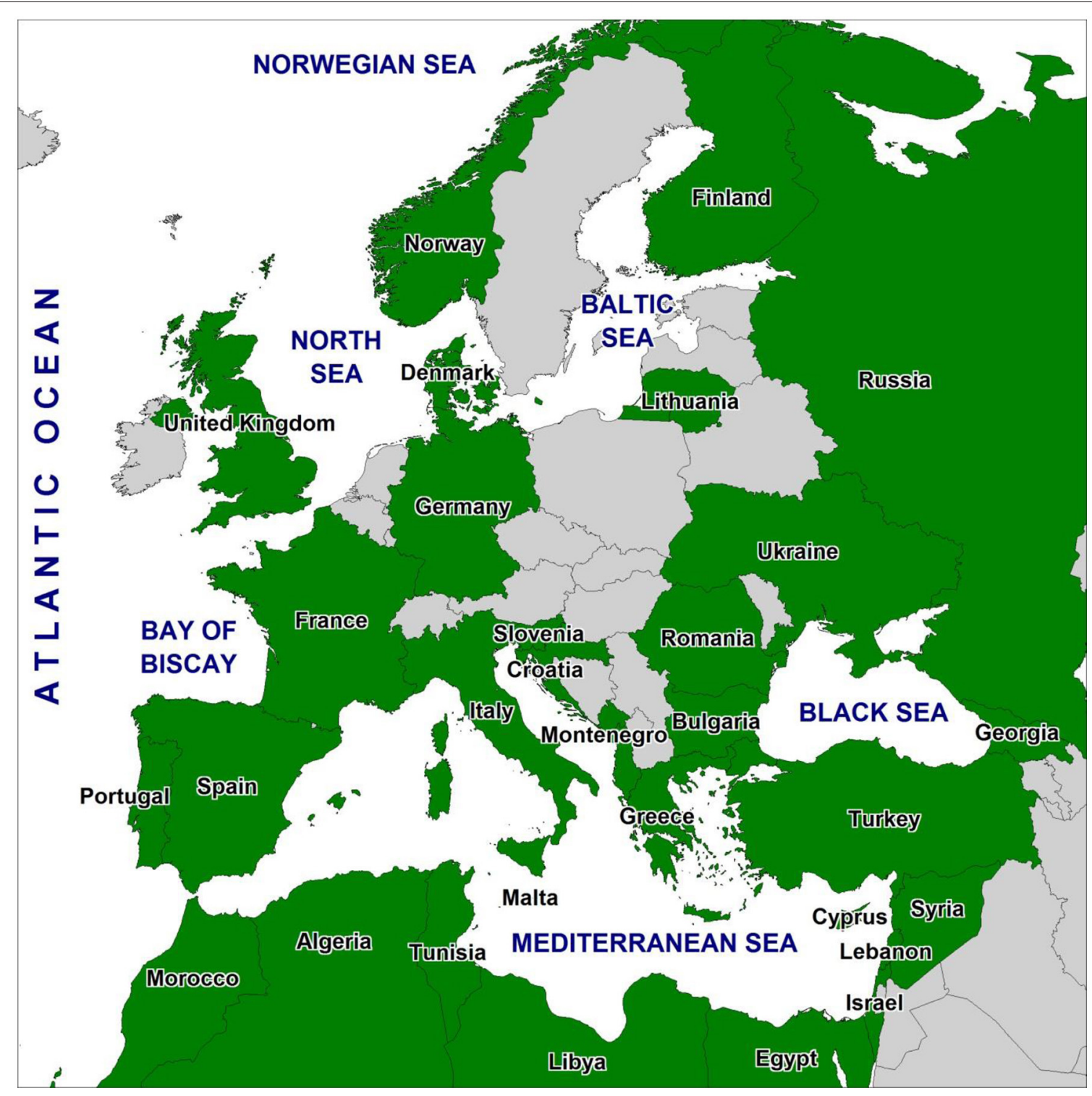

FIGURE 1 | Countries that have information reported in the DEVOTES Catalogue of Monitoring Networks (green) by June 2014 (country borders from Natural Earth database, http://www.naturalearthdata.com).

physico-chemical data table) and details of analytical quality control and quality assurance (AQC/QA, e.g., Gray and Elliott, 2009) were highlighted. Including this information broadly indicates the level of detail, confidence in and quality of a monitoring program, giving information on the nature of the explanatory variables, which may be linked to changes in environmental status. In addition, the information contained in these fields provides the opportunity to link the monitoring activities reported in this catalog to the "Data requirements" fields of the DEVOTES Catalogue of Indicators (Teixeira et al., 2014; available at http://www.devotes-project.eu/devotool/).

The extent to which each program accounts for specific pressures (either directly or indirectly where the biological and physico-chemical parameters indicate environmental change associated with those specific pressures) was identified. Here a pressure was defined as "the mechanism through which an activity has an actual or potential effect on any part of an ecosystem," (Robinson et al., 2008; Scharin et al., 2016). There was a list of 37 pressures, several of which were categorized as local and/or manageable if they were considered to occur as a result of human activities taking place on a localized scale and within the management unit (i.e., a discharge, a specific dredge disposal or aggregate extraction site). The causes and consequences of these pressures can be managed through permits/consents and monitoring. They are referred to as "Endogenic Managed Pressures" where the causes are managed as well as the 
consequences (Elliott, 2011). In contrast, other pressures were categorized as widespread and/or unmanaged, i.e., those that are beyond the control of direct management that are occurring at regional scales and often outside the management unit. For example, temperature and hydrological changes associated with climate change, or $\mathrm{pH}$ change due to volcanic activity (which may be local, but is not manageable). These are referred to as "Exogenic Unmanaged Pressures" where the consequences are managed rather than the causes (Elliott, 2011; Scharin et al., 2016). The MSFD only refers to an incomplete list of endogenic pressures and so the DEVOTES pressures list was produced as a revision from the MSFD and Koss et al. (2011). This adds in the managed and unmanaged pressures, thus allowing climate change to be considered as it has been omitted in MSFD implementation despite the wording of the Directive (Elliott et al., 2015).

(2) Monitoring networks level (group of monitoring programs undertaken or used within broader programs, such as International Conventions, Regional Sea, EU Directives and/or national programs): this entry includes fields relating to cooperation between countries. This level aims to determine whether the monitoring programs undertaken are within a monitoring network of institutions and, if so, what is the monitoring network name, and which other countries are involved in that monitoring network.

(3) Web-platform level: includes details of data provision such as whether the monitoring program provides data to, or takes data from, any international web platform. This level allows the distinction between data sets which are collated in widely accessible formats (i.e., data portal) and those that are collated and stored by individual agencies (these may or may not be accessible on request).

The rationale behind gathering information at the network and web-platform level was to be able to infer whether and if so how EU Member States are optimizing their monitoring plans and efforts.

\section{Data and Information Analysis}

The metadata collated in the catalog were subject to a gap analysis to determine missing aspects and whether the current monitoring is fit-for-purpose both in terms of addressing the MSFD requirements but also wider issues within the marine environment such as providing information for maritime spatial planning, blue growth and industrial marine uses. The monitoring programs undertaken within each Regional Sea (and marine sub-region) were collated and assessed against the descriptors, biodiversity components, habitat types, and pressures to identify any gaps in provision. This led to a SWOT (Strengths, Weaknesses, Opportunities, Threats) analysis to better understand the monitoring networks in Europe, thus allowing us: (1) to explore possibilities for new efforts or solutions to problems specific to the MSFD; (2) to identify opportunities for success in the context of threats to success, clarifying directions and choices, and (3) to make recommendations to overcome the identified impediments and develop more robust monitoring strategies for the future.
Both the gap and the SWOT analyses were performed per marine sub-region (where applicable), marine region and the Pan-European scale (i.e., considering all the activities reported in the catalog). This comprehensive compilation and interrogation allows us to present the main findings that are illustrated by appropriate case studies. More details regarding Regional Sea specific results are given in Patrício et al. (2014, 2015).

\section{RESULTS AND DISCUSSION}

\section{What Are the Types of Monitoring Currently in Place?}

A total of 57 Institutes (including a significant number from outside the DEVOTES project) provided information on monitoring activities. The catalog considers the depth and extent of marine monitoring in 16 EU Member States (Bulgaria, Croatia, Cyprus, Denmark, Finland, France, Germany, Greece, Italy, Lithuania, Malta, Portugal, Romania, Slovenia, Spain, and United Kingdom) and 15 non-EU countries (Albania, Algeria, Egypt, Georgia, Israel, Lebanon, Libya, Montenegro, Morocco, Norway, Russia, Syria, Tunisia, Turkey, and Ukraine) that share European Regional Seas boundaries. The catalog contains 865 entries (i.e., monitoring activities) and $>298$ monitoring programs (some of them with several activities). These activities covered four marine regions (Baltic Sea, Black Sea, Mediterranean Sea, North Eastern Atlantic), 23 sub-regions (as they appear in the MSFD Guidance documents e.g., Bay of Biscay and the Iberian Coast, Greater North Sea, Ionian Sea and the Central Mediterranean Sea, Levantine Sea, etc.), 83 ecological assessment areas (as they appear in national and regional documents e.g., Celtic Sea North, Kattegat and Skagerrak, Northern Adriatic) and also included 37 entries for non-EU waters.

Despite biological monitoring in the Baltic Sea starting in 1979 and being carried out annually in all nine surrounding countries, it was not possible to have an adequate coverage of these monitoring activities in the DEVOTES catalogue. Hence, data reported for the Baltic Sea were deemed insufficient to allow a robust analysis of regional biodiversity monitoring networks. This was mainly due to the low number of partners from the Baltic region in the DEVOTES project, whereas at the same time representatives from the Baltic countries were also involved in another regional pilot project (BALSAM, http://www.helcom. fi/helcom-at-work/projects/balsam) for enhancing the capacity of the Baltic Sea Member States to develop their monitoring programs. The BALSAM project was led by HELCOM, the Regional Sea Convention responsible for coordinating monitoring and assessment of the marine environment in the Baltic Sea. The HELCOM Monitoring and Assessment Strategy (MAS) was endorsed by HELCOM HOD 41/2013 and was adopted by the HELCOM Ministerial Meeting in 2013. A review of monitoring programs resulted in the report and publications (HELCOM, 2013, 2015) and so to complement the scarce regional information obtained from the DEVOTES catalogue, we also used data compiled by HELCOM (2013, 2015). We acknowledge the methodological inconsistency in respect to other European marine regions but we considered 
that it was more acceptable to use these comprehensive reports on the monitoring programs in the Baltic Sea, rather than excluding it. Given the large degree of coordination by the HELCOM countries, in assessing the monitoring activities we assumed that there would be a maximum number of national monitoring programs performed by all Baltic countries (i.e., nine programs) for any element monitored by all states.

Regarding monitoring types, most monitoring reported in the catalog comes under the term surveillance monitoring, ranging from 88 to $94 \%$ in the North Eastern Atlantic (NEA), Mediterranean and Black Sea (Figure 2). There is less condition monitoring which ranged from 6 to $10 \%$ in these three regional seas.

The date at which monitoring started varies widely throughout the catalog (Figure 3) but in general the number of monitoring activities has increased over the last 100 years, with most over the last three decades. Important triggers for monitoring were the Regional Sea Conventions and associated Action Plans. However, there are large differences between Regional Seas, for example, compared to the Baltic Sea and North East Atlantic which had monitoring from the 1970s, there are few monitoring activities in the Mediterranean Sea prior to the 1990s and most Black Sea monitoring programs were initiated in the 2000s.

Throughout the catalog, very different monitoring frequencies are reported, varying from minute to sub-hour, hourly, daily, weekly, twice a month, monthly, bi-monthly, 3-6 times a year, seasonally, 2/3 times a year, twice a year, annual, bi-annual, every 6 years, and up to every 10 years to sporadic, depending on which biodiversity component is the target, the national and international environmental regulations and the budgetary constraints.

\section{Who Does What and How?}

The catalog identified 298 monitoring programs that are suitable to address GES of the MSFD descriptors (i.e., directly or indirectly target the biodiversity-related descriptors). In the NEA, $60 \%$ of monitoring programs are undertaken to fulfill the objectives of European Directives, the OSPAR Convention and other International Conventions (Table 1). Thirty-one percent of these programs address two or more of these legislative drivers and $18 \%$ additionally address national monitoring obligations (Table 1). Most (83\%) of these monitoring programs are undertaken by government agencies and institutions, but $17 \%$ are also undertaken by charities, Non-Governmental Organizations (NGOs) and research institutes (e.g., SAHFOS in Plymouth coordinates the Continuous Plankton Recorder scheme, which has been monitoring plankton since the 1920s and produces most of the data required for plankton in the UK; Table 1). Most of the programs are surveillance monitoring programs (80\%) and generally employ common monitoring protocols, particularly where these programs are undertaken within collaborative monitoring networks [e.g., in the UK the Clean Seas Environment Monitoring Program (CSEMP) previously the National Monitoring Plan (NMP) and the National Marine Monitoring Plan (NMMP)]. In the NEA, 38\% of monitoring programs are undertaken as part of research programs (e.g., MESH-Mapping European Sea beds Habitats, MISTRALS and French POPEX research programs) and/or to address national monitoring obligations (Table 1). These are undertaken by both government agencies (53\%) and NGOs and research institutes (46\%) and are all surveillance monitoring programs (Table 1).

In the Mediterranean Sea, 55\% of the monitoring programs are undertaken because of European legislation [e.g., DCR (Data Collection Framework for the EU Common Fisheries Policy) and WFD; Table 1]. Of these, $13 \%$ addressed two or more legislative drivers and/or research projects. Most programs (66\%) are undertaken by government agencies and institutes (Table 1). The remaining programs are undertaken by NGOs and research institutes and address basin wide issues or more local research projects (e.g., JellyWatch-CIESM Monitoring jellyfish blooms along Mediterranean coasts and in the open sea or NETCETNetwork for the conservation of Cetaceans and Sea Turtles in the Adriatic) and national monitoring (Table 1).

In the Baltic Sea, all of the monitoring programs are undertaken to fulfill the objectives of European Directives, the HELCOM Convention and other International Conventions (Table 1). Most programs (93\%) address two or more of these legislative drivers in addition to national monitoring obligations

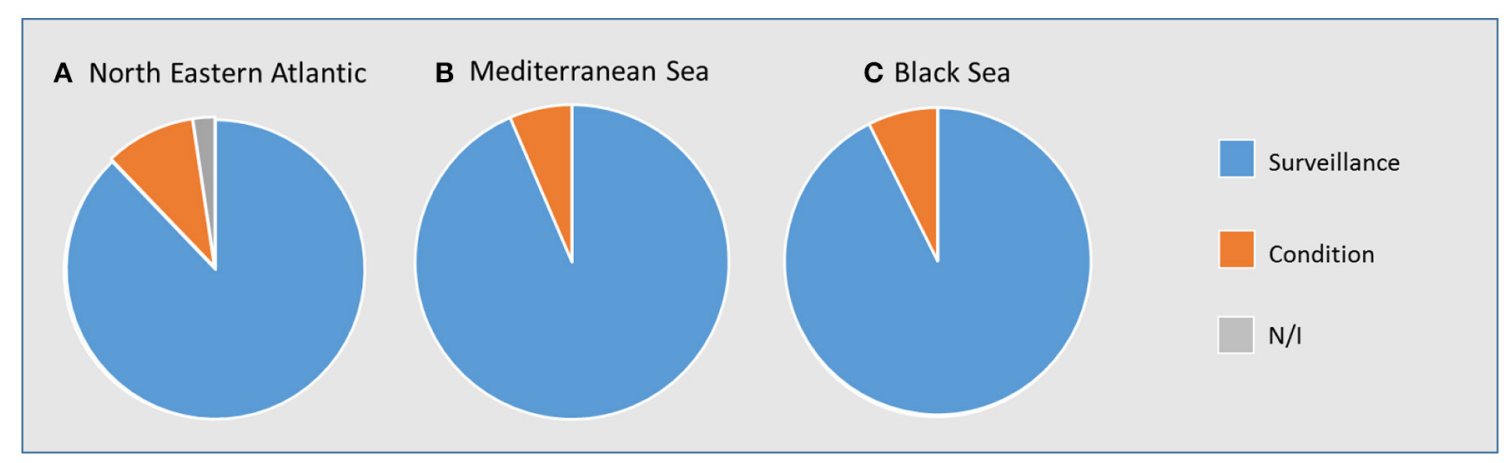

FIGURE 2 | Types of monitoring: condition and surveillance monitoring in the (A). North Eastern Atlantic, (B). Mediterranean Sea and (C). Black Sea. N/I, not identified. 


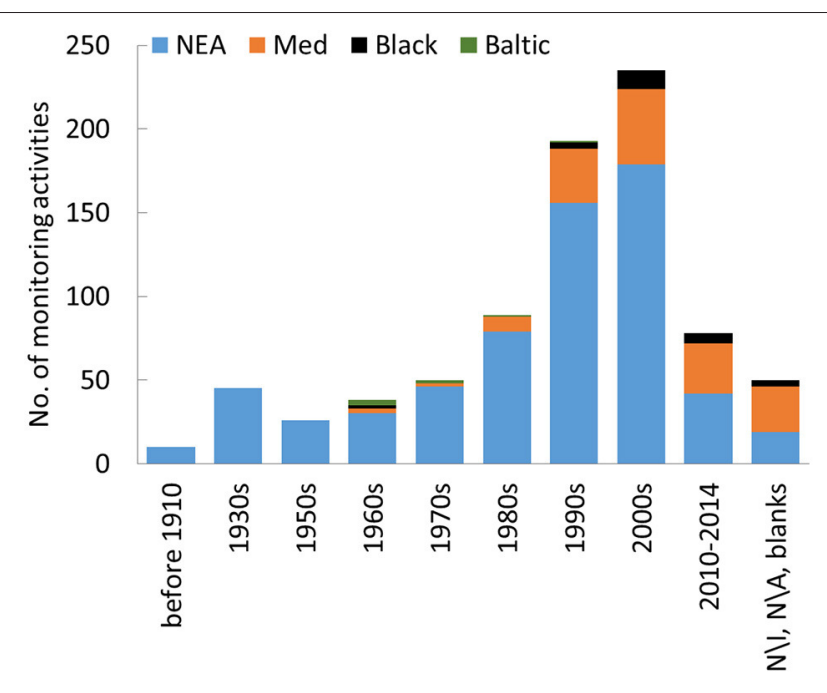

FIGURE 3 | Histogram showing the decades when monitoring activities started in the North Eastern Atlantic (NEA), Mediterranean Sea (Med), Black Sea (Black), and Baltic Sea (Baltic). N/I, not identified, N/A, not applicable.

and, in two cases, research programs. As such, most programs are part of monitoring networks and employ standard monitoring and QA protocols (i.e., HELCOM COMBINE, available at http://www.helcom.fi/action-areas/monitoring-and-assessment/ manuals-and-guidelines/combine-manual). These programs are mainly undertaken by government agencies.

In the Black Sea, most monitoring programs (78\%) address the objectives of European Directives, the Bucharest Convention and other International Conventions in addition to national monitoring and research programs (e.g., World Ocean-in Russia; Table 1). Seventy percent of the monitoring programs are undertaken by governmental agencies and institutes, however $30 \%$ of monitoring is carried out by NGOs and research institutes (Table 1).

\section{Is the Monitoring Fit-For-Purpose for Addressing the MSFD Requirements?}

In the context of the MSFD implementation, as a first step in the preparation of programs of measures, EU Member States across a marine region or sub-region should analyze the characteristics, pressures and impacts in their marine waters (see MSFD Annex III and Commission Decision 2010/477/EU). The second step toward achieving GES should be to establish environmental targets and monitoring programs for ongoing assessment, enabling the state of the marine waters to be evaluated on a regular basis. Hence, it is necessary to question how the monitoring fitness-for-purpose should be assessed. Monitoring has to provide the data to classify a marine area as reaching or failing to reach GES. To do so, the monitoring programs have to accommodate the descriptors, indicative characteristics, pressures, impacts and ideally should be able to provide data for the calculation of the indicators on which GES should be defined. Overall, our analysis showed several areas where current monitoring might not be fit for purpose to address the MSFD requirements.

\section{GES Descriptors}

Monitoring programs which address the descriptors D1biological diversity and D4-food webs are the most numerous in all Regional Seas when taken as a whole, whereas monitoring associated with D2-NIS and D6-seafloor integrity are the least numerous (Figure 4). The distribution of monitoring programs that address these descriptors, however, varies both within and between Regional Seas. In the NEA for example, all descriptors are covered by a large number of monitoring programs in the Greater North Sea and Celtic Seas, however monitoring programs in the Bay of Biscay and the Iberian Coast are less numerous and the limited number of monitoring programs in the Macaronesian biogeographic region is of concern. In the Mediterranean, most of the 35 cataloged activities addressing descriptor D4 have been carried out in the Western Mediterranean, whilst only a limited number of monitoring activities currently addresses this descriptor in the Central and Eastern Mediterranean. In the Black Sea, descriptor D4 is the least monitored descriptor and only three monitoring activities cover it. Regarding monitoring of descriptor D2, few monitoring activities have been reported in all Regional Seas apart from the Greater North Sea and Celtic Seas of the NEA.

Some of the above highlighted gaps were expected. For example, monitoring for non-invasive species was not explicitly required by EU law before the MSFD entered into force although some EU Member States have been collecting data on non-invasive species and using them for coastal water quality assessment. The lack of D2 monitoring agrees with Vandekerkhove and Cardoso (2010) that most monitoring programs fail to detect some indicative NIS. Zampoukas et al. (2014) recommended that existing monitoring programs (e.g., for the WFD) should be complemented to explicitly record NIS and to include high priority sampling sites. Descriptor D6 is covered in all Regional Seas and sub-regions, apart from the Maraconesia biogeographic sub-region where D6 monitoring is lacking, which represents a major gap. Until recently, technical difficulties associated with deep sea sampling (Diaz et al., 2004) and a lack of tradition arising from the absence of effective international measures for assessing and protecting those habitats (Davies et al., 2007) explain why these habitats lag behind in established and complete monitoring programs. This explains why regions dominated by open sea and deep-sea ecosystems may have a poor data availability and hence face a greater difficulty in addressing MSFD D6 requirements.

\section{Biodiversity Components}

In general, monitoring programs which address high trophic level biodiversity components (such as reptiles, mammals, and birds) are lacking or limited in some Regional Seas (e.g., Black Sea and Mediterranean Sea) compared to the NEA (Figure 5). Cephalopod monitoring is limited in all Regional Seas. Monitoring programs addressing fish were not identified as lacking or limited in any Regional Seas although that monitoring is not evenly distributed throughout the sub-categories, with 


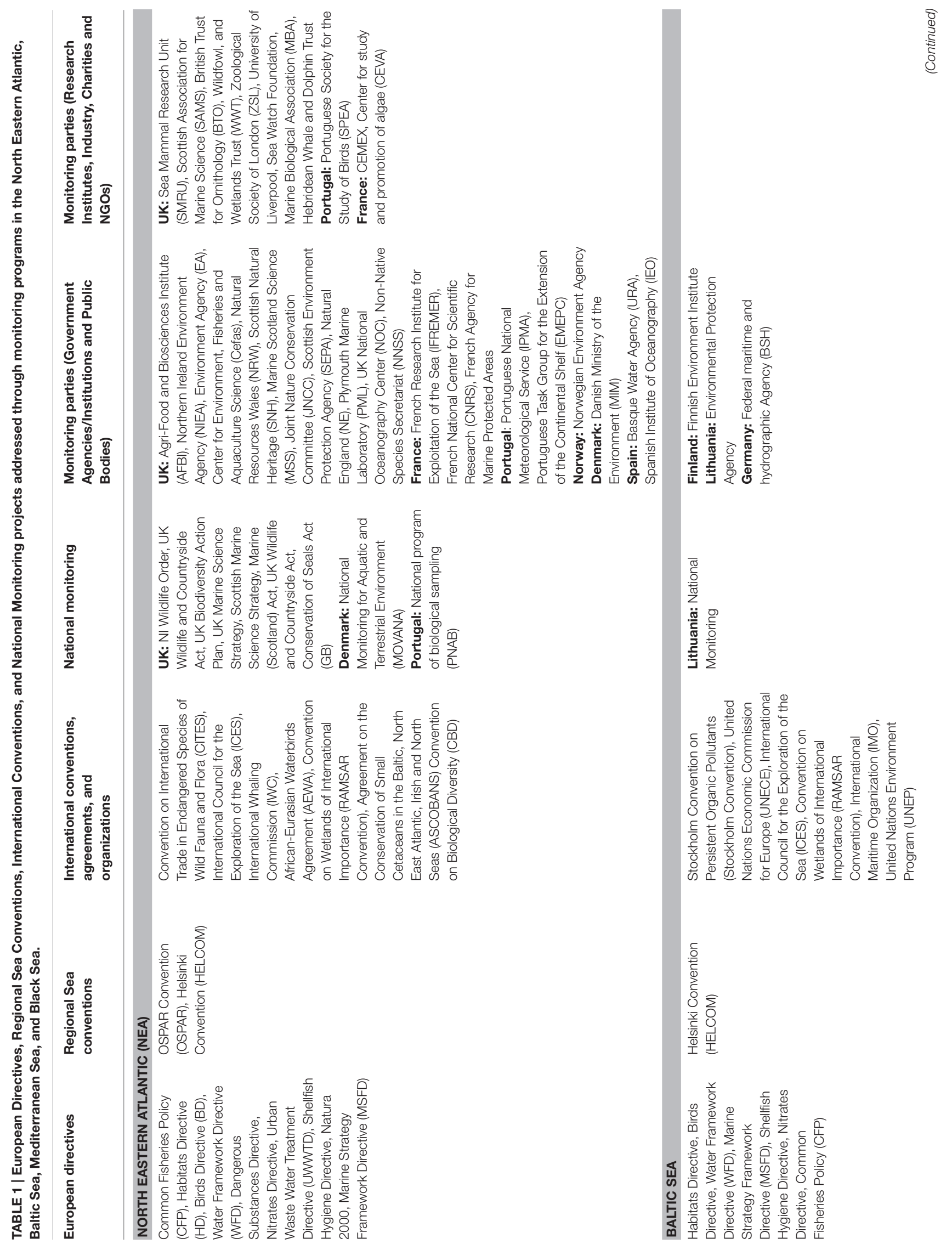




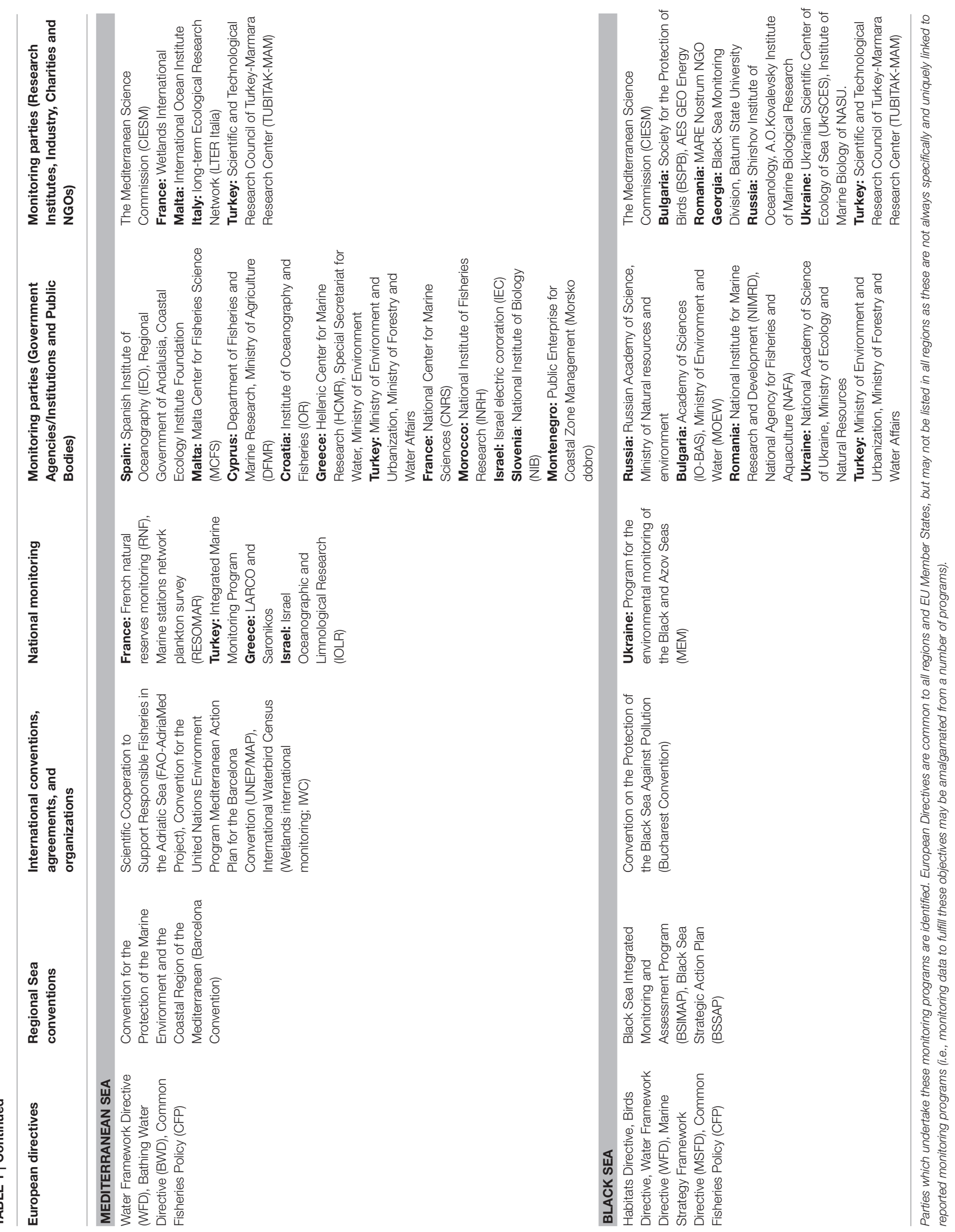




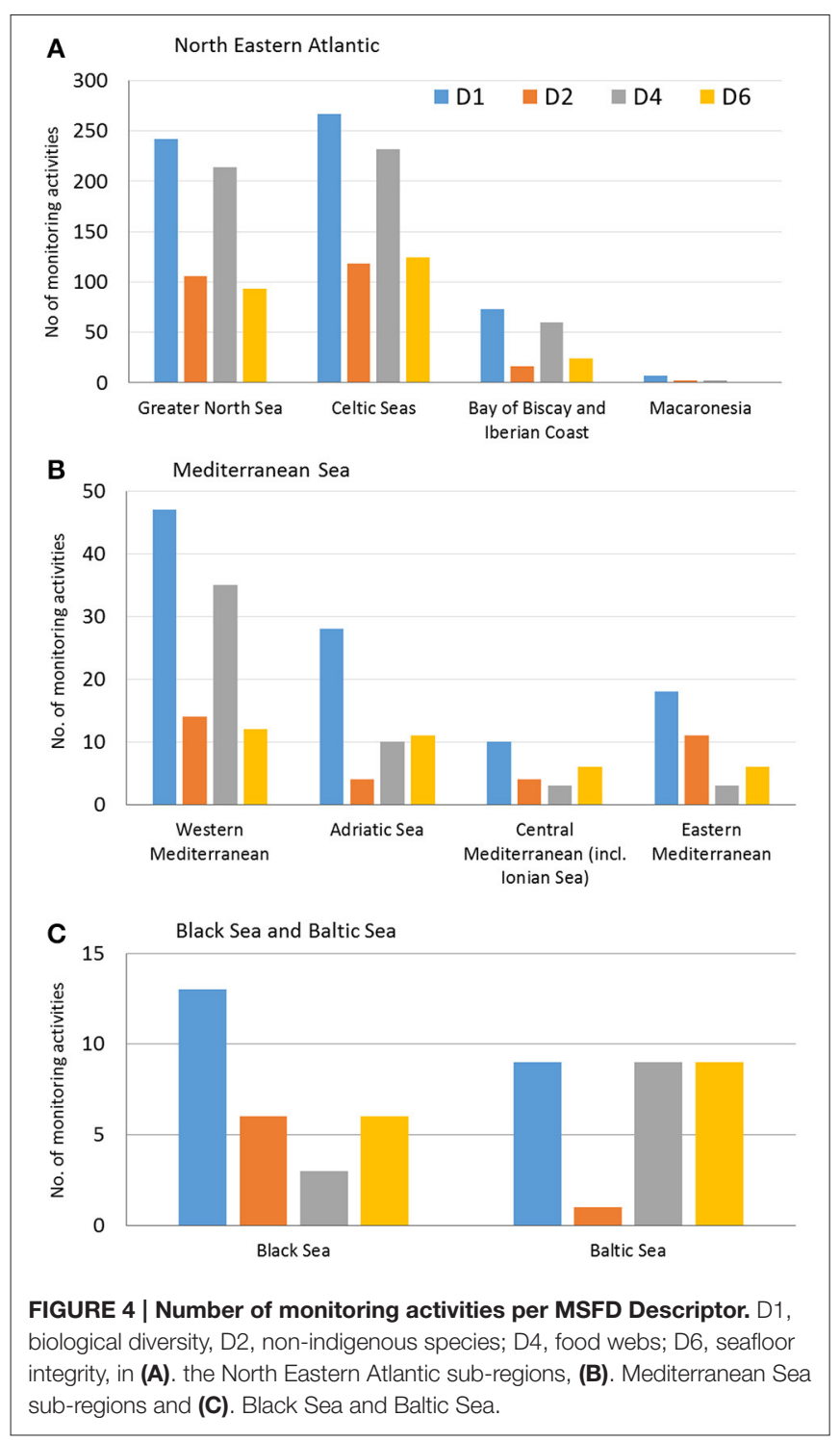

monitoring for deep sea fish, deep sea elasmobranchs, and iceassociated fish lacking or limited to a small number of programs. This pattern is mirrored in the corresponding habitats which lack or have limited monitoring (i.e., deep sea and ice-associated habitats). In addition, most of the fish monitoring focuses on commercial species and less on non-commercial species or is focused on the fish in transitional waters (e.g., estuaries, fjords) as required by the WFD. The limited monitoring for reptiles, mammals, and birds in most Regional Seas was not expected since such monitoring is required in the Habitats and Birds Directives. The same applies to the identified gaps in cephalopod monitoring, expected to be already operational for the Common Fisheries Policy (CFP). Whilst these gaps could be due to incomplete reporting, they may indicate that the implementation of the EU environmental and fisheries related acquis has been limited. However, since some of these components (e.g., mammals) are indeed monitored under the Habitats Directive and regular status updates (every 6 or more years) are freely available through the Article 17 portal for that Directive, it is the lack of access to the monitoring information that represents a problem.

Monitoring programs that address microbes are limited in the NEA and Mediterranean Sea or lacking in the Black Sea (Figure 5). With the exception of microbes, biodiversity components that belong to low trophic levels are generally well addressed by monitoring programs in all Regional Seas, however with a smaller number of offshore stations in all relevant components compared to coastal stations, particularly in the Baltic Sea. Zooplankton monitoring also appears limited in the Mediterranean Adriatic and Central Mediterranean Sea. The lack of microbial diversity monitoring is expected as, with the exception of pathogens in the Bathing Water Directive, it was not previously addressed at the European level. Nevertheless, the overall rather good coverage of low trophic level monitoring could be related to the long European tradition of eutrophication monitoring and to the similar requirements of monitoring eutrophication under the WFD (Ferreira et al., 2011). Similarly, and against a declining trend in monitoring effort, de Jonge et al. (2006) emphasized both the lack on monitoring on these lower trophic components and the lack of monitoring on functioning rather than on structure in marine systems.

\section{Quality Assurance (QA) and Supporting Physicochemical Data}

For a number of biodiversity components QA is lacking. The BEQUALM (Biological Effects Quality Assurance in Monitoring Programmes) and UK NMBAQC (National Marine Biological Analytical Quality Control) schemes respectively for contaminants and benthic invertebrates do provide Analytical Quality Control and QA (Gray and Elliott, 2009) in some Regional Seas (e.g., NEA and Black Sea). However, approximately half of the monitoring activities do not collect supporting physicochemical data which thus provides a major drawback in having sufficient information to explain the ecological findings.

\section{Habitats}

With respect to the seabed and water column, most monitoring activities have been reported to cover "others" instead of a specific habitat from the list. This indicates that these activities cover several habitats and in many instances notes were added including coverage in multiple habitats. The monitoring activities that cover a specific seabed habitat are most numerous for "littoral sediment" in the NEA, and Mediterranean and Black Seas. In total, 10 seabed habitats have not been reported to be covered by monitoring activities. Nevertheless, these habitats might be covered by the monitoring activities which have been reported to cover "others" (i.e., 256 activities in the NEA, 22 in the Mediterranean and four in the Black Sea). In the water column, the NEA monitoring activities cover all five habitats and the Mediterranean activities cover four habitats (i.e., "variable salinity (estuarine) water" is not covered). In the Black Sea only "marine water: coastal" and "marine water: shelf" are indicated to be covered by monitoring activities but these may be regarded as "catch-all" terms. As with seabed habitats, the water column habitats which do not seem to be covered could be monitored 


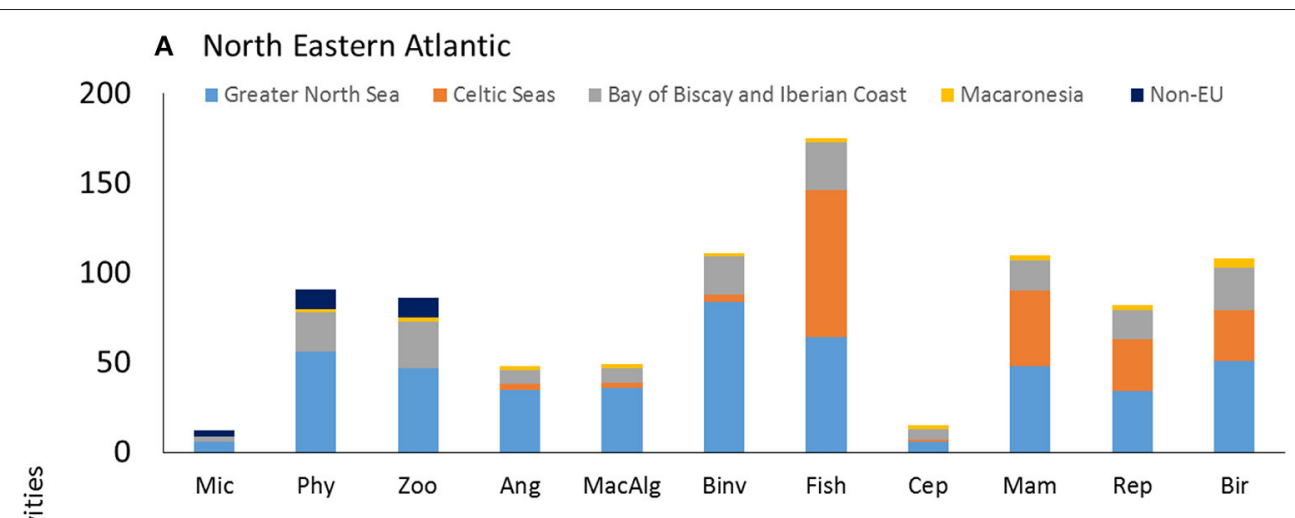

B Mediterranean Sea
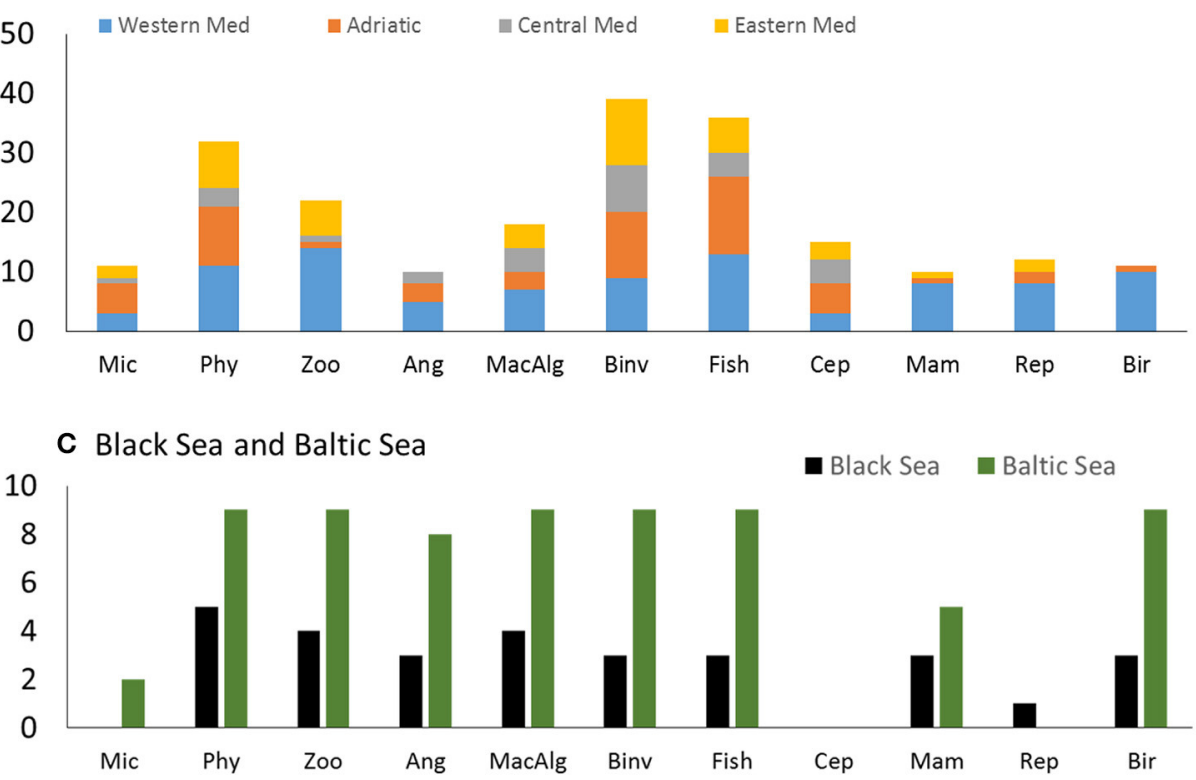

FIGURE 5 | Number of monitoring activities per biological component in (A). The North Eastern Atlantic sub-regions, (B). Mediterranean Sea sub-regions and (C). Black Sea and Baltic Sea. Mic, microbes; Phy, phytoplankton; Zoo, zooplankton; Ang, angiosperms; MacAlg, macroalgae; Binv, benthic invertebrates; Cep, cephalopods; Mam, marine mammals; Rep, marine reptiles; Bir, marine birds; Western Med, Western Mediterranean; Central Med, Central Mediterranean including the lonian Sea; Eastern Med, Eastern Mediterranean.

through activities that include "others" (i.e., 383 in the NEA, 32 in the Mediterranean and three in the Black Sea), however, as stated above this could not be verified. Monitoring programs addressing ice-associated habitats are recorded as completely lacking on those Regional Seas where these habitats occur (NEA and Baltic), which could be partially attributed to the monitoring activities targeting this habitat indirectly through monitoring focusing in the ice-associated species or communities (e.g., seals; Teixeira et al., 2014), but also to a lack of input from more Northern countries.

\section{Pressures}

In the Greater North Sea and Celtic Sea (NEA), all 37 pressures are covered by monitoring activities (Figure 6A). In the Baltic Sea, 26 pressures are covered. Although there are between 11 and 25 pressures covered in the Mediterranean, in the Black Sea, and in the NEA sub-regions Bay of Biscay and Iberian Coast and Macaronesia, the actual number of monitoring activities covering these pressures is limited when compared to the Greater North Sea and Celtic Sea (North Eastern Atlantic; Figure 6A).

Despite it being an individual MSFD descriptor (D11introduction of energy), monitoring programs addressing the pressure "underwater noise" are limited in the Baltic Sea and Black Sea (i.e., only one monitoring activity reported) and lacking in the Bay of Biscay and Iberian Coast and Macaronesia (both NEA) and the Mediterranean (Figure 6B). At present, the impact of noise on many biodiversity components is not well understood (e.g., Roberts et al., 2015) and the outputs of such monitoring cannot be used effectively. Also the pressures "marine litter," "noise," and "introduction of non-indigenous species" are mainly monitored in the NEA and coverage is limited in other regional seas. The limitation in monitoring activities for the first 


\section{A Number of pressures covered}

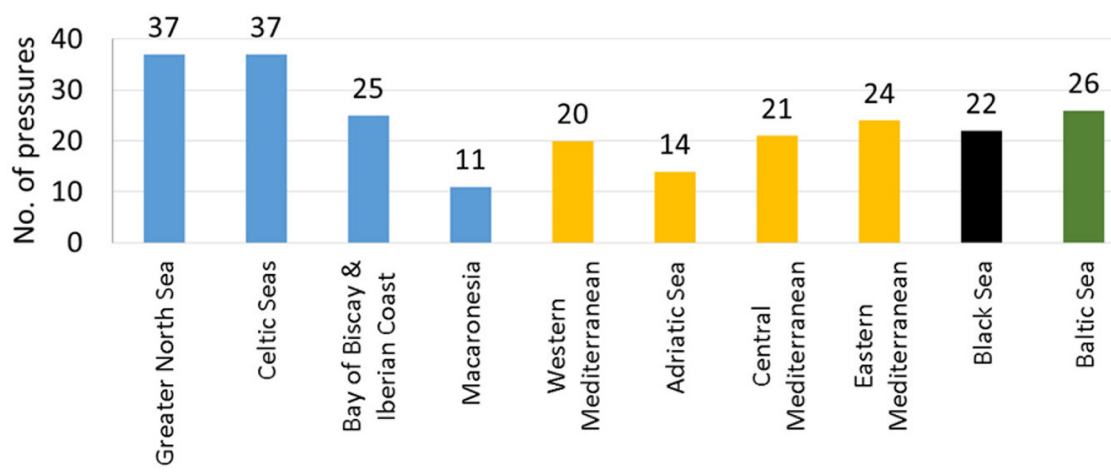

\section{B Number of monitoring activities per pressure}

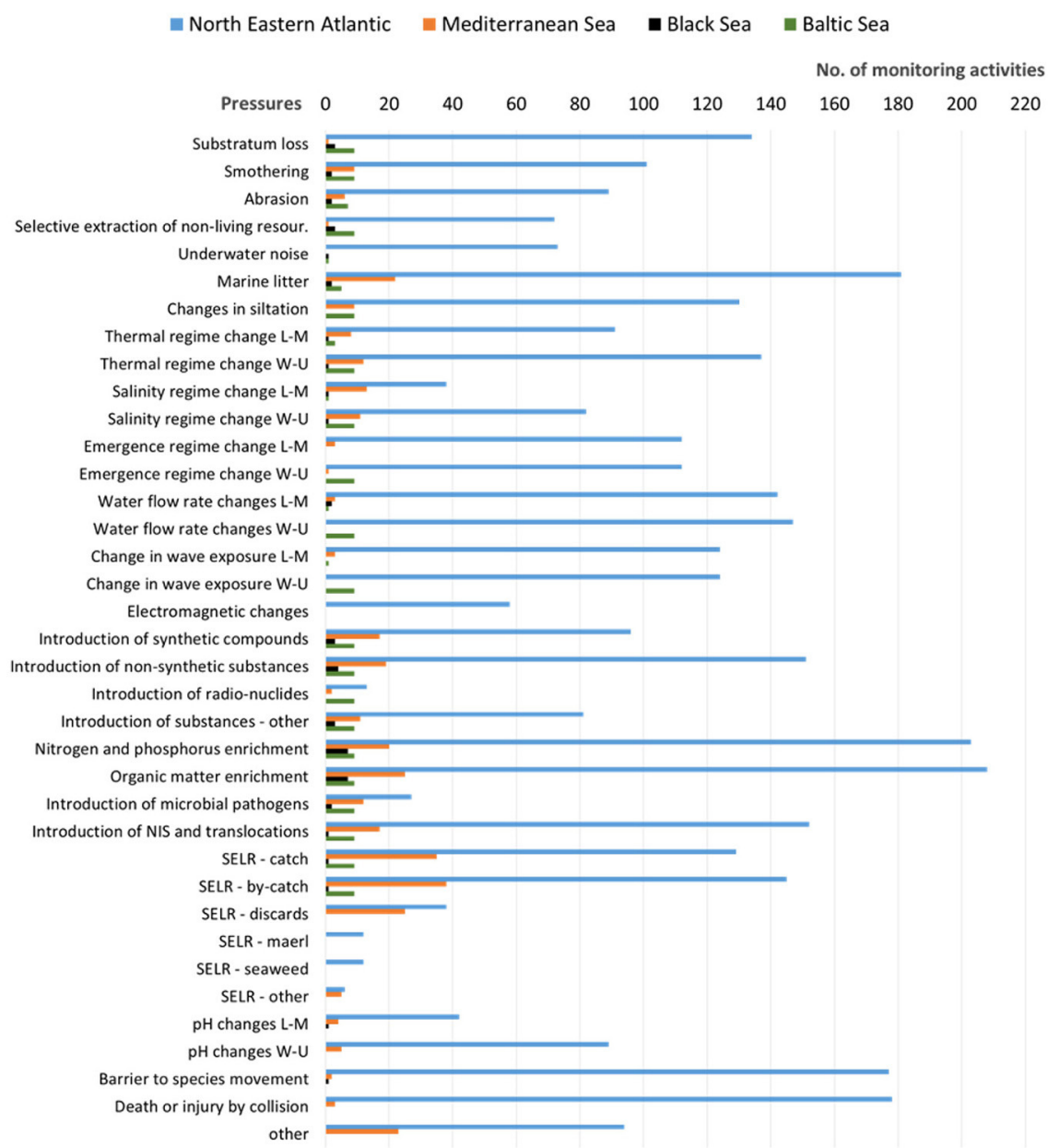

FIGURE 6 | (A) Number of pressures covered and (B). Number of monitoring activities per pressure in the North Eastern Atlantic (sub-regions: Greater North Sea, Celtic Seas, Bay of Biscay, and Iberian Coast, Macaronesia), Mediterranean Sea (sub-regions: Western Mediterranean, Adriatic Sea, Central Mediterranean including the Ionian Sea, Eastern Mediterranean), Black Sea, and Baltic Sea. L-M, Local and manageable; W-U, Widespread and unmanageable; SELR, Selective extraction of living resources.

two of these pressures in the catalog represents a partial gap as they are directly linked to MSFD descriptors not targeted by this catalog (i.e., D10-marine litter and D11-introduction of energy). In the Baltic Sea, until systematic non-indigenous species (NIS) monitoring programs (Lehtiniemi et al., 2015) and port biological sampling (HELCOM, 2013) are routinely 
established with wider Baltic coverage, the primary sources for NIS occurrence, their distribution and population size estimates remain non-systematic and include "inherent uncertainty" as this information depends on data collection for other purposes than NIS surveillance. Therefore, one of the major issues still to be solved is the establishment of an internationally coordinated monitoring system for NIS/Cryptogenic Species in the Baltic Sea and in other areas (Olenin et al., 2011). However, because of the high degree of concern regarding NIS emanating from the Suez Canal into the Mediterranean Sea, then this has resulted in more information available for parts of the Mediterranean Sea (Galil et al., 2014).

Monitoring programs addressing the pressures "water flow rate changes (widespread-unmanageable)," "change in wave exposure (widespread-unmanageable)," and "electromagnetic changes" are also lacking in the Black Sea and the Mediterranean Sea. Similarly, the pressure "introduction of radionuclides" is generally limited or lacking in all regional seas although this is incorporated into compliance monitoring (as conditions under their license to operate) carried out by nuclear power and reprocessing authorities and industries.

Monitoring for the "selective extraction of living resources," the pressures "catch," "bycatch," and "discards" is covered in the NEA, Baltic Sea and Mediterranean Sea, but lacking or limited in the Black Sea. The coverage of these pressures could be due to the fact that they are also being monitored through the EU Common Fisheries Policy and Data Collection Framework. Activities monitoring the pressures "maerl extraction" and "seaweed extraction" are limited in the NEA and lacking in the Mediterranean and Black Sea (there is limited commercial extraction and production in those areas).

\section{What Are the Strengths and Weaknesses of the Existing Marine Biodiversity Monitoring in Europe? \\ Strengths}

As indicated above, there is a long history of monitoring in the European Regional Seas which has enabled the standardization of techniques and the development of best practice. For example, in the NEA and the Baltic Sea, monitoring starts from the early 1900s and in all Regional Seas at least some monitoring has taken place since the 1950s, with the number of programs increasing to the present day. Monitoring started to become more coordinated in the 1970s with the formation of HELCOM for the Baltic Sea and the Oslo and Paris Conventions (now OSPAR) for the NEA. Within each Regional Sea, it is generally common practice to collect supporting physico-chemical data simultaneously with biological data in order to explain biological change and several programs have associate formal QA guidelines to ensure validity of the data. Furthermore, for the four MSFD descriptors considered, all biodiversity components, habitats and pressures are addressed to some extent in all Regional Seas, with some programs addressing multiple descriptors. This provides a strong basis for the implementation of the MSFD and the assessment of GES. In most Regional Seas, the 11 biodiversity components are being covered and several are monitored simultaneously. Similarly, most monitoring programs concurrently address more than one seabed and water column habitat, thus optimizing the sampling efforts and providing an holistic approach to environmental monitoring. In general, most monitoring programs address more than one pressure. Although these are exceptions, some monitoring activities assess 18-20 pressures simultaneously (e.g., Celtic Sea sub-region), suggesting the potential for monitoring programs to become more efficient.

\section{Weaknesses}

Whilst the information in the catalog has enabled a broad spatial and temporal assessment of monitoring throughout Europe, it cannot be used to assess completely the adequacy of monitoring although it does identify areas which require further development. For example, whilst it is apparent that all descriptors, habitats and biodiversity components are being addressed, this is only the case for certain areas of some Regional Seas (e.g., in the territorial waters of a single nation). Detailed analysis at the individual Regional Sea level highlights this uneven distribution of monitoring activities at a spatial (sampling sites and stations) and temporal (sampling interval and frequency) level. Additionally, in a number of sub-regions, marine biodiversity monitoring programs address a specific target only (e.g., a particular habitat, species, pressure, etc.) resulting in an uneven distribution of monitored components (i.e., not all components are monitored in all sub-regions). For example, the NEA sub-regions Greater North Sea and Celtic Sea have the most reported monitoring activities of all Regional Seas; in contrast the NEA sub-region Macaronesia has a limited number of monitoring activities and contains several major gaps (e.g., no monitoring activities of D2 and D6). This may be partially an artifact of an incomplete coverage of the catalog, but it still reflects significant imbalances. It may also reflect the fact that monitoring historically has been driven by the presence or societal perception of problems, i.e., if society considers there to be an environmental problem then the authorities are more likely to respond and similarly pristine areas are not deemed to require extensive (if at all) monitoring (de Jonge et al., 2006).

In this broad-scale assessment, the number of monitoring programs that simultaneously address biodiversity components, descriptors, habitats and pressures (managed and unmanaged) is used in our study as a measure of the robustness of ongoing monitoring to potentially meet the requirements of the MSFD (to achieve GES) in all Regional Seas. However, whilst there is much information indicating the presence/absence of supporting physico-chemical data and QA to support this, detailed information on sampling design, sampling frequency, methodology, and the status of the QA programs (e.g., is it a national/international programs which includes assessment of the performance of participants?) is required to assess whether or not the monitoring is fit-for-purpose. Indeed, whilst monitoring in some areas is well developed, the associated indicators for the MSFD assessment of some descriptors are still under development indicating a weakness that needs to be addressed before the requirements of the MSFD can be fully met (Teixeira et al., 2014). Integrated monitoring is more likely to capture intricate ecological relationships, while 
at the same time the identification of anthropogenic cascade effects and cumulative or in-combination effects may be better identified if monitoring is coordinated in time and space. This includes bottom-up processes and top-down responses, and thus an analysis of ecosystem functioning as well as ecosystem structure, which underpins the Ecosystem-based approach, a central pillar of the MSFD and marine management (Elliott, 2014). Several monitoring programs both within and between regional seas address single or a limited number of components, habitats and pressures and although not explicitly investigated within the catalog, may be limited in terms of spatial (e.g., geographic area, sampling locations) and temporal (time-series, sampling frequency) scale. There is a need for more efficient and robust monitoring programs, integrating several biodiversity components, habitats and pressures through simultaneous monitoring, especially where pressures emanate through the whole ecosystem. Additionally, despite the extensive system of monitoring programs in most Regional Seas, a number of biodiversity components (e.g., microbes), descriptors (e.g., NIS), habitats (e.g., ice or deep sea habitats) and pressures (e.g., noise, introduction of radionuclides, selective extraction of living resources such as seaweed and maerl) are poorly or not addressed. Furthermore, most monitoring is focused on ecosystem structural aspects (the number of species, size of population, cover by a species) rather than on functional aspects (rate processes) even though the MSFD may change this emphasis (Borja et al., 2010; Hering et al., 2010).

The weaknesses identified are not trivial, as they concern some of the most relevant and elemental attributes of sound biodiversity monitoring schemes, recently identified by Pocock et al. (2015), for example, articulate objectives, standardized methodology, suitable field sampling methods, taxonomic literature, national, or regional coordination, data entry systems, QA of data, or/and scientific sampling design. Similarly, monitoring has to provide the 18 attributes for creating sound indicators and monitored elements given by Elliott (2011). Nevertheless, these findings can be used to reassess priorities when planning development or adjustment of the biodiversity monitoring programs in the future.

\section{What Are the Threats and Opportunities of the Existing Marine Biodiversity Monitoring in Europe? \\ Threats}

Budgetary constraints are the most significant and obvious threat to monitoring within EU Member States (e.g., Borja and Elliott, 2013) thus giving rise to what has been termed the "monitoring requirement paradox," that there is an increasing amount of governance requiring monitoring while at the same time monitoring budgets have been cut (Borja et al., 2016; Strong and Elliott, accepted). For example, even where monitoring is undertaken within networks with standardized protocols (e.g., MEDITS and MEDPOL), budgetary constraints can result in countries suffering from data gaps over several years (see also de Jonge et al., 2006).
As identified above, achieving GES through the implementation of the MSFD is only attainable if the current and future monitoring of marine biodiversity is improved in all European Regional Seas. The number of ecosystem components monitored needs to be increased and specific monitoring programs developed to analyze pressures and pressure-impact relationships (Scharin et al., 2016). It may also be necessary to standardize sampling methods, increase sampling frequency and intensify sampling design in some regional seas. In order to ensure successful integrative monitoring schemes within and between Regional Seas, it may be necessary to establish a sustainable funding scheme and/or research budget and a rapid response/intervention framework. In the current economic climate it is difficult to envisage that EU Member States would be able to provide an appropriate budget for this but at present there is no pan-European or EU mechanism for funding monitoring across Member States. It is likely to remain the case that funding within a given area is the responsibility of that Member State.

The integration and holistic assessment of monitoring data at the Regional Sea level may be difficult, time consuming and economically restrictive due to methodological differences between EU Member States. This is also partly due to some EU Member States having a long history of monitoring and where many programs have been expanded, modified and developed over time. Hence, rather than establish new monitoring programs which specifically address MSFD objectives, EU Member States may rely on existing programs, which may be inadequate or not suitable, particularly where these have been designed for other purposes. Hence, when required to submit their MSFD monitoring proposals in 2014, EU Member States appear to report what they were doing rather than what they were required to do additionally for the directive (Boyes and Elliott, 2014), an approach which is expected to lead to anomalies and gaps (Boyes et al., 2016). In addition, differences in methods between countries which then need to produce a uniform assessment, will then need inter-calibration and inter-comparison exercises as has been carried out during the implementation of the EU WFD (e.g., Hering et al., 2010; Lepage et al., 2016).

Regional cooperation is required between EU Member and Non-Member States to implement the MSFD (Cavallo et al., 2016), although Non-Member States are under no legislative requirement to achieve GES in their respective regional seas. However, sea areas controlled by a combination of Member States and Non-Member States will still require coordination to tackle transboundary problems; this will certainly be the case for any current Member State which leaves the EU (Boyes and Elliott, 2016). If agreements with Non-Member States are not in place, achieving this cooperation may put undue additional pressure on EU Member States and may mean that infractions (proceedings in the European Court that a Member State has failed to meet a Directive) cannot be prosecuted and GES in the Regional Sea may not be achieved. For example, Norway is a non-Member State of the EU therefore not implementing the MSFD but it is still performing many of the aspects required by the Directive as well as being a leading member of OSPAR and following its monitoring and assessment protocols. Accordingly Regional Sea Conventions 
have an important role in this coordination, for example through the OSPAR, HELCOM, and UNEP/MAP monitoring and assessment programs.

\section{Opportunities}

Several inadequacies have been identified in the monitoring currently undertaken in the Regional Seas. This presents a number of opportunities to modify and/or expand existing monitoring programs, develop new programs and to collaborate between EU Member States to develop standardized and robust programs and networks. These can occur both within and between Regional Seas that maximize the use of the best available data.

This would mean, for example, standardized verification of analyses and species identification, inter-calibration exercises for hazardous substance concentrations in biota, introduction and/or integration of validated external QA protocols, and a focus on upgrading the spatial and temporal resolution of monitoring and inter-calibration procedures. Introducing the simultaneous monitoring of descriptors, biodiversity components, habitats and pressures within single, large monitoring programs and ensuring that monitoring is designed to address specific pressures would increase the robustness of monitoring. This may also give an opportunity to create an online bank of all monitoring program data, accessible to all EU Member States, which should include information collected under different Directives and research programs (e.g., CFP, WFD, MSFD, EU funded projects, etc.). Creating such a uniform data storage system is being accomplished both at an EU scale, e.g., through the European Environment Agency and EMODnet (http://www.emodnet.eu/), and at an EU Member State level such as MEDIN in the UK (see http://www.oceannet.org/).

Those EU Member States that are members of Regional Sea Conventions (RSC) with a long history of marine monitoring and assessment, such as OSPAR and HELCOM, which have had joint monitoring programs since the 1970s, can provide valuable experience to states with a lesser history. The opportunity for collaborative work afforded by the implementation of the MSFD enables EU Member and Non-Member States to improve and/or develop monitoring programs to achieve GES in some regional seas (i.e., the Black Sea, Mediterranean Sea). This regional cooperation may prove essential for achieving GES in Regional Seas that border non-EU nations. For example, non-EU Member States of the Black Sea and Mediterranean Sea, respectively, should be encouraged through the Black Sea Commission and UNEP/MAP to develop more integrated monitoring programs (especially for the descriptors related to biodiversity monitoring). However, costs associated with activities required by RSC are borne by the country and so each country is required to fund its own commitments. Despite this, funding is becoming increasingly available from the $\mathrm{EU}$, for example, to develop Integrated Regional Monitoring Implementation Strategies in the Mediterranean and Black Seas and basin-wide promotion of MSFD principles (PERSEUS and IRIS-SES projects). However, funding the development of strategies and principles may not be the same as funding the monitoring. Accordingly, our findings regarding the inadequacies in the monitoring currently undertaken in the European regional seas form the basis of further research proposals and requirements.

\section{Conclusions and Recommendations to Overcome the Identified Impediments and Develop More Robust Monitoring Strategies for the Future}

The MSFD explicitly spells out that the assessment strategy is to be implemented at the regional or sub-regional level with both the individual EU Member States and, whenever possible, third countries (sharing the regions/sub-regions) acting together coherently and in a coordinated fashion through regional institutional cooperation structures. The success of the MSFD depends on a high level of cooperation between EU Member States, third countries and regional bodies mandated with environmental protection responsibilities (Long, 2011; Cavallo et al., 2016). Monitoring programs are to be compatible within marine regions or sub-regions and monitoring methods are to be consistent so as to facilitate comparability of monitoring results (Karydis and Kitsiou, 2013). The MSFD further specifies that standardized methods for monitoring and assessment be adopted (Zampoukas et al., 2013) thus putting the onus on the activities of the EU Member States, through coordination by the Regional Sea Conventions and even between RSC. Although there is some detail as to the descriptors or types of biological and other components that should be monitored, given that the MSFD is a Framework Directive, then the method of monitoring is left to the EU Member State level. This can create a large variation and incompatibility between, for example, two EU Member States that share marine borders within the same Regional Sea. There has always been a North and West compared to South and East difference within Europe with the former areas having more developed regional governance and organization, more detailed and long-standing administrative/legislative frameworks, a longer history and culture of environmental management and greater resources. A complicating feature is in the make-up of the Regional Seas, where in northern Regional Sea areas EU Member States comprise more than $80 \%$ of the participants compared to the Mediterranean and Black Sea regional areas where EU Member States make up less than $40 \%$ of the participant states. In the latter cases therefore, reaching GES for the whole region would require substantive support from the non-EU Member States, the relevant RSC and the EU Member States. The northern RSC (HELCOM and OSPAR) have a much longer experience of coordinated monitoring than the southern ones (UNEP/MAP, Black Sea Commission) and the western Member States have a longer history of compliance with EU environmental Directives than the eastern states. Hence, as all Member States have to implement and comply with the Directives then the intent of the MSFD needs to be reinforced to provide a much stronger level of clear coordination and standardization in the southerly Regional Seas (Zampoukas et al., 2013).

We acknowledge that the database on which the analysis here is based has some omissions and that the regional and national monitoring effort is changing annually. Despite that, we consider 
that the major and general lessons learned from its interrogation are robust and will hold even for a more complete database. As such, we strongly recommend the following:

1. Specific coordination within the Regional Sea MSFD monitoring programs-this will require specific Regional Sea committees/representation/meetings with EU Member States and non-Member States to discuss, agree and set up detailed Regional Sea recommendations, guidelines and specific implementation plans. In turn, this will allow for the growth of large, coordinated datasets for the (sub)regions of each Regional Sea, and, in a near future, will allow establishing a common platform for data sharing (resulting from different Directives and EU policies, e.g., EMODnet) that should be compulsory for all EU Member States.

2. Standardization of methodologies, based on the follow-on from Regional Sea meeting workshops, on selection, set-up of protocols and training, for:

a) Choice of indicators for each of the descriptors, including coverage of under-monitored components (e.g., microbes) and to monitor functional as well as structural aspects;

b) Developing methods which can cover large sea areas more efficiently (e.g., landers, gliders and seabed scanning) and provide the surveillance monitoring against which future investigative and diagnostic monitoring is carried out when marine environmental adverse effects are detected;

c) Design of spatial and temporal coverage for indicator measurement (including replication) which includes reconciling the compromise between monitoring effort and the capability of detecting impacts;

d) More effective methodologies for sampling, sample processing and analysis to produce data for the selected indicators (or proxies for those indicators), and

e) Quality assurance/control of the sampling and analytical process and using inter-comparison and inter-calibration exercises where necessary and where possible.

3. EU Member States to specifically budget for sufficient monitoring and coordination activities but ensure these are cost-effective. Borja and Elliott (2013) have noted that the consequence of the choices made now, during times of economic crisis, increases the possibility that European countries will not produce useful information for management. To avoid this and to maximize information gained relative to resources required for data collection and analysis, Levine et al. (2014) and Franco et al. (2015) suggest that sampling designs should be established to account for uncertainty analyses, thus improving the efficiency of environmental monitoring. Such designs would have to be statistically based, perhaps using power analysis, against the required detection limits and thresholds of effect (Franco et al., 2015). There is a mismatch between Member States concerning size of area of marine responsibility and their existing capabilities/resources and at present there appears to be no facility for centralized EU funding for monitoring nor for the transfer of monitoring funds across Member States from those with better resources to less-advantaged Member
States. However, Member States can cooperate and one can even carry out monitoring on behalf of another.

Monitoring programs under the MSFD must be compatible with assessment obligations arising from other regional and EU or international instruments for reasons of continuity and efficiency (Long, 2011). While it is easy for an EU Member State to adapt or extend an existing monitoring program, they need to be fitfor-purpose with at least the minimum requirement to ensure adequate, defendable and meaningful assessments. Given that there is likely to be an increasing litigious framework, where assessments may be challenged legally in infraction proceedings (e.g., see Elliott et al., 2015), then the monitoring and resultant data have to be robust to those challenges.

As some of the descriptors or components may be new to established traditional monitoring [e.g., D2-NIS (e.g., see Olenin et al., 2011) and D11-introduction of energy-underwater noise (e.g., Roberts et al., 2015)] or as trends move from structural to functional ecosystem aspects (e.g., Strong et al., 2015), there is the need to develop/adopt cost-effective and innovative methods for monitoring including both state-of-the-art methods/tools and citizen science. Complementing existing monitoring programs for example for the EU WFD to explicitly deal with gap-filling on invasive species is recommended (Zampoukas et al., 2014) as well as integrating assessments made under the Habitats and Birds Directives for mammals, reptiles and birds.

Although, as shown here, there is a good basis on which to build, several EU Member States will need to broaden the scope and expand monitoring coverage and intensity to comprehensively assess the environmental status of their waters. Integrated monitoring programs taking into account a common vision on operational objectives and on indicators and targets for GES, are needed to achieve and maintain a particular or minimum desired level of environmental quality (Cinnirella et al., 2012) at the regional level. In addition, as the protection of the environment and the conservation of marine ecosystems functioning are now rooted in the EU regulatory code as binding legal obligations (Long, 2011; Boyes and Elliott, 2014), standards and protocols also need to be enacted to make the assessments strong, robust and legally defensible if challenged. It is emphasized and acknowledged that while many of the recommendations given here require better, more extensive and perhaps more costly monitoring, this is required to avoid any legal challenges to the assessments or to bodies and industries accused of causing a deterioration in marine quality.

Finally, it is emphasized that the detection of GES rest wholly on the adequacy of monitoring and the ability to detect a signal of change against a background of inherent variability, and conversely that inadequate monitoring will not be able to determine either such a change or determine whether management measures have had the desired effect.

\section{AUTHOR CONTRIBUTIONS}

JP led the work on the manuscript. JP, SL, KM, KP, CS, $\mathrm{HH}$ compiled data, analyzed data (status, gaps, and SWOT), 
conceived, structured and wrote the manuscript. JP and $\mathrm{HH}$ constructed the figures. HT and KM built the catalog, compiled data, wrote the manuscript. MU, OS, AZ, GK, OK, TC, SM, MB collected data to fill in the catalog, did the regional data analysis and status/gaps/SWOT and contributed to the manuscript. AB, $\mathrm{NH}$ contributed to and revised the manuscript. ME envisioned the need for the monitoring catalog, wrote and revised the manuscript.

\section{ACKNOWLEDGMENTS}

This manuscript is a result of DEVOTES (DEVelopment Of innovative Tools for understanding marine biodiversity and

\section{REFERENCES}

Berg, T., Fürhaupter, K., Teixeira, H., Uusitalo, L., and Zampoukas, N. (2015). The Marine Strategy Framework Directive and the ecosystembased approach-pitfalls and solutions. Mar. Pollut. Bull. 96, 18-28. doi: 10.1016/j.marpolbul.2015.04.050

Borja, A., and Elliott, M. (2013). Marine monitoring during an economic crisis: the cure is worse than the disease. Mar. Pollut. Bull. 68, 1-3. doi: 10.1016/j.marpolbul.2013.01.041

Borja, A., Elliott, M., Andersen, J. H., Cardoso, A. C., Carstensen, J., Ferreira, J. G., et al. (2013). Good environmental status of marine ecosystems: what is it and how do we know when we have attained it? Mar. Pollut. Bull. 76, 16-27. doi: 10.1016/j.marpolbul.2013.08.042

Borja, Á., Elliott, M., Carstensen, J., Heiskanen, A.-S., and van de Bund, W. (2010). Marine management - towards an integrated implementation of the european marine strategy framework and the water framework directives. Mar. Pollut. Bull. 60, 2175-2186. doi: 10.1016/j.marpolbul.2010.09.026

Borja, A. B., Elliot, M., Snelgrove, P. V. R., Austen, M. C., Berg, T., Cochrane, S., et al. (2016). Bridging the gap between policy and science in assessing the health status of marine ecosystems. Front. Mar. Sci. 3:175. doi: 10.3389/fmars.2016.00175

Boyes, S. J., and Elliott, M. (2014). Marine legislation - the ultimate 'horrendogram': international law, European directives \& national implementation. Mar. Pollut. Bull. 86, 39-47. doi: 10.1016/j.marpolbul. 2014.06.055

Boyes, S. J., and Elliott, M. (2016). Brexit: the marine governance horrendogram just got more horrendous!. Mar. Pollut. Bull. doi: 10.1016/j.marpolbul.2016.08.020. [Epub ahead of print].

Boyes, S. J., Elliott, M., Murillas-Maza, A., Papadopoulou, N., and Uyarra, M. C. (2016). Is existing legislation fit-for-purpose to achieve Good Environmental Status in European seas? Mar. Pollut. Bull. doi: 10.1016/j.marpolbul.2016.06.079. [Epub ahead of print].

Cavallo, M., Elliott, M., Touza-Montero, J., and Quintino, V. (2016). The ability of regional coordination and policy integration to produce coherent marine management: implementing the Marine Strategy Framework Directive in the North-East Atlantic. Mar. Policy 68, 108-116. doi: 10.1016/j.marpol.2016.02.013

Cinnirella, S., March, D., O’Higgins, T., Murciano, C., Sardà, R., Albaigés, J., et al. (2012). A multidisciplinary spatial data infrastructure for the Mediterranean to support the implementation of the Marine Strategy Framework Directive. Int. J. Spat. Data Infrastruct. Res. 7, 323-351. doi: 10.2902/1725-0463.2012.07.art16

Davies, A. J., Roberts, J. M., and Hall-Spencer, J. (2007). Preserving deep-sea natural heritage: emerging issues in offshore conservation and management. Biol. Conserv. 138, 299-312. doi: 10.1016/j.biocon.2007.05.011

de Jonge, V. N., Elliott, M., and Brauer, V. S. (2006). Marine monitoring: its shortcomings and mismatch with the EU Water Framework Directive's objectives. Mar. Pollut. Bull. 53, 5-19. doi: 10.1016/j.marpolbul.2005.11.026

Diaz, R. J., Solan, M., and Valente, R. M. (2004). A review of approaches for classifying benthic habitats and evaluating habitat quality. J. Environ. Manage. 73, 165-181 doi: 10.1016/j.jenvman.2004.06.004 assessing Good Environmental Status) project, funded by the European Union under the 7th Framework Program, "The Ocean of Tomorrow" Theme (grant agreement no. 308392), www.devotes-project.eu. María C. Uyarra is partially funded through the Spanish program for Talent and Employability in $\mathrm{R}+\mathrm{D}+\mathrm{I}$ “Torres Quevedo." The authors gratefully acknowledge the help and metadata information received from the Regulatory Authorities within each EU Member State, the DEVOTES partnership and numerous non-DEVOTES experts. A list of non-DEVOTES experts that have contributed for the DEVOTES Catalogue of Monitoring Networks (June 2014 version) is available at http://www.devotes-project.eu/wp-content/uploads/ 2014/10/list-of-experts_june2014.pdf.

EC (2010). EU Commission Decision of 1 September 2010 on Criteria and Methodological Standards on Good Environmental Status of Marine Waters (2010/477/EU). O.J. 232, 14-24. Brussels: EU Commission Decision.

EC (2011). Commission Staff Working Paper - Relationship between the Initial Assessment of Marine Waters and the Criteria for Good Environmental Status. 14.10.2011. SEC(2011) 1255 final. Brussels: EU Commission Decision.

EC (2012). Commission Staff Working Paper - Guidance for 2012 Reporting under the Marine Strategy Framework Directive, using the MSFD Database Tool, 164. Version 1.0. Brussels: DG Environment.

Elliott, M. (2011). Marine Science and management means tackling exogenic unmanaged pressures and endogenic managed pressures - a numbered guide. Mar. Pollut. Bull. 62, 651-655. doi: 10.1016/j.marpolbul.2010.11.033

Elliott, M. (2014). Integrated marine science and management: wading through the morass. Mar. Pollut. Bull. 86, 1-4. doi: 10.1016/j.marpolbul.2014.07.026

Elliott, M., Borja, A., McQuatters-Gollop, A., Mazik, K., Birchenough, S., Andersen, J. H., et al. (2015). Force majeure: will climate change affect our ability to attain Good Environmental Status for marine biodiversity Mar. Pollut. Bull. 95, 7-27. doi: 10.1016/j.marpolbul.2015.03.015

Ferreira, J. G., Andersen, J. H., Borja, A., Bricker, S. B., Camp, J., Cardoso da Silva, M., et al. (2011). Overview of eutrophication indicators to assess environmental status within the European Marine Strategy Framework Directive. Est. Coast. Shelf Sci. 93, 117-131. doi: 10.1016/j.ecss.2011.03.014

Franco, A., Quintino, V., and Elliott, M. (2015). Benthic monitoring and sampling design and effort to detect spatial changes: a case study using data from offshore wind farm sites. Ecol. Indic. 57, 298-304. doi: 10.1016/j.ecolind.2015. 04.040

Galil, B. S., Marchini, A., Occhipinti-Ambrogi, A., Minchin, D., Narščius, A., Ojaveer, H., et al. (2014). International arrivals: widespread bioinvasions in European Seas. Ethol. Ecol. Evol. 26, 152-171. doi: 10.1080/03949370.2014.897651

Gray, J. S., and Elliott, M. (2009). Ecology of Marine Sediments: Science to Management. Oxford: Oxford University Press.

HELCOM (2013). Overview of the Marine Environmental Monitoring in the Baltic Sea. HELCOM MORE project report. HELCOM Secretariat. Available online at: http://iris-ses.eu/wp-content/uploads/2014/03/MORE_monitoring.pdf

HELCOM (2015). Improving the Coordination in the Monitoring of the Baltic Marine Environment. BALSAM project final report. Secretariat. Available online at: http://www.helcom.fi/BALSAM\%20publications/BALSAM \%20Project\%20Final\%20Report.pdf

Hering, D., Borja, A., Carstensen, J., Carvalho, L., Elliott, M., Feld, C. K., et al. (2010). The European Water Framework Directive at the age of 10: a critical review of the achievements with recommendations for the future. Sci. Total Environ. 408, 4007-4019. doi: 10.1016/j.scitotenv.2010.05.031

Karydis, M., and Kitsiou, D. (2013). Marine water quality monitoring: a review. Mar. Pollut. Bull. 77, 23-36. doi: 10.1016/j.marpolbul.2013.09.012

Koss, R. S., Knights, A. M., Eriksson, A., and Robinson, L. A. (2011). ODEMM Linkage Framework Userguide. ODEMM Guidance Document Series No.1. EC FP7 project (244273) 'Options for Delivering Ecosystem-based Marine Management'. University of Liverpool. 
Lehtiniemi, M., Ojaveer, H., David, M., Galil, B., Gollasch, S., McKenzie, C., et al. (2015). Dose of truth - monitoring marine non-indigenous species to serve legislative requirements. Mar. Policy 54, 26-35. doi: 10.1016/j.marpol.2014.12.015

Lepage, M., Harrison, T., Breine, J., Cabral, H., Coates, S., Galván, C., et al. (2016). An approach to intercalibrate ecological classification tools using fishin transitional water of the North East Atlantic. Ecol. Indic. 67, 318-327. doi: 10.1016/j.ecolind.2016.02.055

Levine, C. R., Yanai, R. D., Lampman, G. G., Burns, D. A., Driscoll, C. T., Lawrence, G. B., et al. (2014). Evaluating the efficiency of environmental monitoring programs. Ecol. Indic. 39, 94-101. doi: 10.1016/j.ecolind.2013.12.010

Long, R. (2011). The marine strategy framework directive: a new european approach to the regulation of the marine environment, marine natural resources and marine ecological services. J.Energy Nat. Rersour. Law 29, 1-44. doi: 10.1080/02646811.2011.11435256

Olenin, S., Elliott, M., Bysveen, I., Culverhouse, P., Daunys, D., Dubelaar, G. B. J., et al. (2011). Recommendations on methods for the detection and control of biological pollution in marine coastal waters. Mar. Poll. Bull. 62, 2598-2604. doi: 10.1016/j.marpolbul.2011.08.011

Patrício, J., Little, S., Mazik, K., Thomson, S., Zampoukas, N., Teixeira, H., et al. (2014). Report on SWOT Analysis of Marine Monitoring Networks. DEVOTES FP7 project; JRC89561. Available online at: http://www.devotes-project.eu/ deliverables-and-milestones/

Patrício, J., Papadopoulou, N., Zenetos, A., and Smith, C. (2015). "Marine biodiversity monitoring currently used in the Mediterranean Sea: is the monitoring for the MSFD fit-for-purpose?" in Proceedings of the 11th Panhellenic Symposium on Oceanography and Fisheries (Mytilene), 589-592.

Pocock, M. J., Newson, S. E., Henderson, I. G., Peyton, J., Sutherland, W. J., Noble, D. G., et al. (2015). Developing and enhancing biodiversity monitoring programs: a collaborative assessment of priorities. J. Appl. Ecol. 52, 686-695. doi: 10.1111/1365-2664.12423

Roberts, L., Cheesman, S., Breithaupt, T., and Elliott, M. (2015). Sensitivity of the mussel Mytilus edulis to substrate-borne vibration in relation to anthropogenically-generated noise. Mar. Ecol. Prog. Ser. 538, 185-195. doi: 10.3354/meps 11468

Robinson, L. A., Rogers, S., and Frid, C. L. J. (2008). A Marine Assessment and Monitoring Framework for Application by UKMMAS and OSPAR - Assessment of Pressures and Impacts. Phase II: Application for regional assessments. Joint Nature Conservation Committee contract No. C-08-0007-0027.

Scharin, H., Ericsdotter, S., Elliott, M., Turner, R. K., Niiranen, S., Rockström, J., et al. (2016). Processes for the sustainable stewardship of marine environments. Ecol. Econ. 128, 55-67. doi: 10.1016/j.ecolecon.2016.04.010
Shephard, S., van Hal, R., de Boois, I., Birchenough, N. R. S., Foden, J.-, O'Connor, J., et al. (2015). Making progress towards integration of existing sampling activities to establish Joint Monitoring Programmes in support of the MSFD. Mar. Policy 59, 105-111. doi: 10.1016/j.marpol.2015.06.004

Strong, J. A., Andonegi, E., Bizsel, K. C., Danovaro, R., Elliott, M., Franco, A., et al. (2015). Marine biodiversity and ecosystem function relationships: the potential for practical monitoring applications. Est. Coast. Shelf Sci. 161, 46-64. doi: 10.1016/j.ecss.2015.04.008

Strong, J. A., and Elliott, M. (accepted). The need for modern imaging techniques in supporting spatial extrapolation. Mar. Pollut. Bull.

Teixeira, H., Torsten, B., Fürhaupter, K., Uusitalo, L., Papadopoulou, N., Bizsel, K. C., et al. (2014). Existing Biodiversity, Non-Indigenous Species, Food-Web and Seafloor Integrity Gens Indicators (Devotes Deliverable 3.1) Devotes FP7 Project. Available online at: http://www.devotes-project.eu/deliverables-andmilestones/

Vandekerkhove, J., and Cardoso, A. C. (2010). Alien Species and the Water Framework Directive - Questionnaire Results. JRC Scientific and Technical Report.

Zampoukas, N., Piha, H., Bigagli, E., Hoepffner, N., Hanke, G., and Cardoso, A. C. (2013). Marine monitoring in the European Union: how to fulfill the requirements for the Marine Strategy Framework Directive in an efficient and integrated way. Mar. Policy 39, 349-351. doi: 10.1016/j.marpol.2012.12.004

Zampoukas, N., Palialexis, A., Duffek, A., Graveland, J., Giorgi, G., Hagebro, C., et al. (2014). Technical Guidance on Monitoring for the Marine Strategy Framework Directive. JRC Scientific and Policy Report. Available online at: http://publications.jrc.ec.europa.eu/repository/bitstream/111111111/ 30508/1/lb-na-26499-en-n.pdf

Conflict of Interest Statement: The authors declare that the research was conducted in the absence of any commercial or financial relationships that could be construed as a potential conflict of interest.

The handling Editor declared a collaboration with the authors and states that the process nevertheless met the standards of a fair and objective review.

Copyright (c) 2016 Patrício, Little, Mazik, Papadopoulou, Smith, Teixeira, Hoffmann, Uyarra, Solaun, Zenetos, Kaboglu, Kryvenko, Churilova, Moncheva, Bučas, Borja, Hoepffner and Elliott. This is an open-access article distributed under the terms of the Creative Commons Attribution License (CC BY). The use, distribution or reproduction in other forums is permitted, provided the original author (s) or licensor are credited and that the original publication in this journal is cited, in accordance with accepted academic practice. No use, distribution or reproduction is permitted which does not comply with these terms. 